\title{
Effect of Type 2 Diabetes Mellitus and Diabetic Nephropathy on IgG Pharmacokinetics and Subcutaneous Bioavailability in the Rat
}

\author{
Gurkishan S. Chadha ${ }^{1}$ and Marilyn E. Morris ${ }^{1,2}$
}

Received 11 March 2015; accepted 9 April 2015; published online 30 April 2015

\begin{abstract}
The objective of this research was to assess the effects of type 2 diabetes mellitus (T2DM) and diabetic nephropathy (DN) on the pharmacokinetics of human $\operatorname{IgG}(\mathrm{hIgG})$, an antibody isotype, in Zucker diabetic fatty (ZDF) rats. Furthermore, the specific role of T2DM in the altered disposition of $\mathrm{hIgG}$ was evaluated by treating diabetic rats with pioglitazone, while the role of chronic kidney disease (CKD) was assessed using 5/6 nephrectomized Sprague Dawley rats. ZDF male (lean non-diabetic control and obese diabetic) and pioglitazone-treated ZDF rats were studied at ages 12-13 weeks (only DM was present), and at ages 29-30 weeks (progression to DN). All animals were dosed with $1 \mathrm{mg} / \mathrm{kg}$ of hIgG intravenously (IV) or subcutaneously (SC). ZDF rats had significantly higher blood glucose concentrations and urinary albumin excretion compared to control rats. Significant increases in total clearance (2.5-fold) and renal clearance ( 100 -fold) of hIgG were observed; however the major increase in total clearance was due to increased non-renal clearance. Greater changes in urinary albumin excretion and total and renal clearances of $\operatorname{IgG}$ (3.5-fold and 300-fold, respectively) were observed with progression to DN. SC bioavailability of $\mathrm{hIgG}$ in all animal groups was similar $(>84 \%)$. With pioglitazone-treatment, diabetic animals remained euglycemic and treatment was able to reverse the clearance changes, although incompletely. In the CKD group, no difference in hIgG clearance was observed when compared with controls. In conclusion, the increased clearance of hIgG in ZDF diabetic animals, reversal by pioglitazone treatment and lack of effect of $\mathrm{CKD}$, demonstrate the influence of T2DM on hIgG pharmacokinetics.
\end{abstract}

KEY WORDS: antibody; chronic kidney disease; renal clearance; urinary albumin excretion; Zucker diabetic fatty rat.

\section{INTRODUCTION}

Diabetes mellitus is one of the most common endocrine metabolic disorders. As of 2010, around 285 million people were affected globally with diabetes, with type 2 diabetes mellitus (T2DM) making up about $90 \%$ of the cases. The prevalence of T2DM is further estimated to reach around 500 million people worldwide by $2030(1,2)$. Approximately one third to one fourth of T2DM patients develop diabetic nephropathy (DN) $(3,4)$. As DN progresses, there is an increase in urinary albumin excretion, observed as microalbuminuria and progressing to macroalbuminuria $(4,5)$. Furthermore, after onset of DN, about $20 \%$ of individuals will progress to endstage renal diseases (ESRD) $(6,7)$.

Significant effects of DM/DN on small molecules have been reported, but there are only a few studies that have evaluated the impact of $\mathrm{DM} / \mathrm{DN}$ on the pharmacokinetics (PK) of antibodies (8). Although the prevalence of

\footnotetext{
${ }^{1}$ Department of Pharmaceutical Sciences, School of Pharmacy and Pharmaceutical Sciences, University at Buffalo, State University of New York, Buffalo, New York 14214-8033, USA.

${ }^{2}$ To whom correspondence should be addressed. (e-mail: memorris@buffalo.edu)
}

microalbuminuria and macroalbuminuria is significant with T2DM, only a limited number of studies have evaluated the alteration in renal elimination and urinary concentrations of proteins and macromolecules such as $\operatorname{IgG}(9,10)$. In one study, Pima Indians with T2DM and DN demonstrated a greater than twofold increase in urinary $\operatorname{IgG}$ concentrations compared to individuals without significant microalbuminuria (10). In another study, changes in the total clearance of adalimumab in patients with focal segmental glomerulosclerosis $(n=7)$ was reported to be two- to fivefold higher, with non-renal clearance contributing more to the change in total clearance than renal clearance (11). Additionally, diabetic co-morbidity in psoriatic patients resulted in a $28.7 \%$ higher clearance $(\mathrm{CL} / \mathrm{F})(12)$. Significant increases in the clearance of $8 \mathrm{C} 2$ (a murine monoclonal antibody) have been observed with type $1 \mathrm{DM}$ in streptozotocin-treated mice. These changes were positively correlated with changes in urinary albumin excretion and glomerular filtration rates (13).

Given that DM and chronic kidney disease (CKD) represent common co-morbidities, through the development of DN, our aim in this study was to assess the effects of T2DM and CKD, alone and concomitantly, on human IgG (hIgG) PK. IgG is the most abundant antibody isotype found in the circulation, and therefore is used in the current studies 
as representative of monoclonal antibodies (14). Studies were performed in Zucker diabetic fatty (ZDF) rats at different stages of T2DM: early (ages 12-13 weeks) without evidence of DN, and at later times (ages 29-30 weeks) in the presence of DN. We evaluated the progressive changes in blood glucose, urinary function, and hIgG pharmacokinetics and subcutaneous bioavailability after the administration of IV and SC doses of hIgG. Given the reported changes in the disposition of small molecules with diabetes progression, we hypothesize that diabetes will also lead to alterations in the pharmacokinetics of human IgG in ZDF rats. Furthermore, we hypothesize that diabetic nephropathy may also contribute to the alterations in the PK of $\mathrm{hIgG}$ in diabetes.

\section{MATERIALS AND METHODS}

\section{Chemicals, Reagents, and Kits}

Human IgG was purchased from Sigma-Aldrich (St. Louis, Missouri). Ketamine and xylazine were obtained from Henry Schein (Melville, New York). Pioglitazone (TEVA Pharmaceuticals) was purchased commercially.

\section{Animals}

Male Zucker diabetic fatty (ZDF) rats (Charles River, Wilmington, MA) were used for all experiments examining $\mathrm{DM}$ and DM/DN. The animals consisted of ZDF male $+/$ ? lean (non-diabetic control rats, $n=15$ ) and ZDF male FA/FA obese (obese diabetic rats, $n=25$ ). Animals were housed under controlled temperature and humidity with an artificial 12-h light/dark cycle. Animals were allowed to acclimate to their environment for one week prior to surgical implantation of jugular vein cannulae under anesthesia with ketamine/ xylazine $(75 / 10 \mathrm{mg} / \mathrm{kg})$. Cannulae were flushed daily with $40 \mathrm{IU} / \mathrm{mL}$ heparinized saline to maintain patency. Animals were allowed a minimum of $72 \mathrm{~h}$ for recovery from surgery before drug administration. Sprague Dawley CD ${ }^{\circledR}$ rats [male, 10 weeks of age, 5 weeks after surgery] either with or without (sham) 5/6 nephrectomy surgery (n=8) were used (Charles River, Wilmington, MA) for the CKD study. These animals were independently housed for 5 weeks before drug administration. All animal protocols were approved by the Institutional Animal Care and Use Committee at the University at Buffalo.

\section{Study Design}

Diabetes Studies. ZDF rats were chosen as our animal model of type $2 \mathrm{DM} / \mathrm{DN}$ as they exhibit the pertinent clinical signs of this disease including initial DM and progression to DN, allowing for the assessment of the effects of DM with and without renal dysfunction, as well as with concomitant obesity. Male obese ZDF rats become obese, insulin resistant, and progress to non-insulin dependent diabetes around the ages of 8-14 weeks due to a leptin receptor defect. These animals develop progressive DN causally related to their DM and represent a well-characterized animal model of DM/DN $(15,16)$. Non-diabetic Zucker rats were used as age-matched controls. At the age of 9 weeks, the ZDF male FA/FA obese rats were divided into two further groups. One group was the untreated diabetic group with free access to food. The second group was the pioglitazone-treated group, treated with $10 \mathrm{mg} / \mathrm{kg}$ pioglitazone orally daily throughout the study to normalize blood glucose levels (15). The average food consumption of diabetic animals was calculated as amount consumed per day, and the same amount of food was then given to the pioglitazone-treated rats, so that food intake was the same. Animals were weighted and blood (through saphenous vein) and urine samples were collected throughout the studies to characterize the hyperglycemia and renal function of the animals. The disposition of $\mathrm{hIgG}$ was studied at the age of 12-13 weeks (phase A; the observed age for the development of diabetes in the ZDF obese diabetic model) and then at the age of 29-30 weeks (phase B; when the ZDF diabetic rats demonstrated nephropathy with progressive albuminuria and rising urinary albumin to creatinine ratios (ACR)) $(15,17)$. Animals were dosed with $1 \mathrm{mg} / \mathrm{kg}$ of $\mathrm{hIgG}$ IV (dissolved in $0.9 \%$ saline) through the jugular cannula or penile vein or SC (in the flank region). Since the SC studies resulted in lower plasma concentrations of $\mathrm{hIgG}$, additional phase A studies, with ZDF rats at 13 weeks of age, were performed with a lower dose of $\mathrm{hIgG}(0.2 \mathrm{mg} / \mathrm{kg})$ administered IV in order to determine if the clearance of hIgG was changed at lower plasma concentrations. Additionally, in order to evaluate the disposition of endogenous rat $\mathrm{IgG}(\mathrm{rIgG})$ in the non-diabetic control, diabetic- and pioglitazone-treated diabetic rats, plasma concentrations, and urinary excretion amounts of endogenous $\mathrm{rIgG}$ were determined in all three groups of animals.

CKD Study. The control (sham surgery) and 5/6 nephrectomized rats were used in these studies. Between 5 and 12 weeks, the 5/6 nephrectomized rats demonstrated increasing nephropathy with progressive albuminuria and rising ACR $(18,19)$. At 10 weeks of age (with surgery performed at 5 weeks of age), the animals were dosed with $1 \mathrm{mg} / \mathrm{kg}$ of hIgG IV or SC (in the flank region).

\section{Sample Collection}

Baseline blood samples were analyzed for biomarkers of disease progression including blood glucose, blood urea nitrogen, and urinary albumin and creatinine. Post dosing hIgG, blood $(200 \mu \mathrm{L})$, and urine samples were obtained from all animals every day for 4-5 half-lives. Blood samples were collected from the saphenous vein and urine was collected using metabolic cages.

\section{Analysis of Human and Rat IgG, Blood Glucose, BUN, Albumin, and Creatinine}

Blood glucose and BUN were determined using a VetScan Analyzer. hIgG plasma and urine concentrations were measured using an anti-human IgG ELISA kit (Bethyl Labs Inc. Montgomery, TX). No cross-reactivity of the ELISA for $\operatorname{rgG}$ has been reported by the manufacturer, nor did we find cross-reactivity when analyzing standards in various rat matrices. Rat plasma and urine were diluted (1:100 to $1: 10$ and $1: 2$, respectively) by sample diluent and an ELISA assay was performed following the manufacturer's 
instructions (GenWay, San Diego, CA). Standard curves were created in the individual matrices and were in range of 3.91$250 \mathrm{ng} / \mathrm{mL}$. These were fitted to a four-parameter logistic model. Quality control samples (250 and $50 \mathrm{ng} / \mathrm{mL}$ ) of $\mathrm{hIgG}$ in blank matrices were run simultaneously to test for between-assay variability. To be certain that the ELISA method was sensitive toward intact hIgG only, the urine samples were microcentrifuged (with $100 \mathrm{kDa}$ filters) so that the smaller molecular weight fragments of hIgG ( $<100 \mathrm{kDa})$ would be filtered out. Our studies demonstrated that greater than $90 \%$ of the $\mathrm{hIgG}$ concentration determined by the ELISA was intact hIgG; thus, breakdown fragments of hIgG were not confounding the results. Similarly, rat albumin and creatinine ELISAs (GenWay, San Diego, CA) were used for plasma and urine analysis with the specific kits used according to the manufacturer's instructions.

\section{Pharmacokinetic Model}

Human IgG $(1 \mathrm{mg} / \mathrm{kg})$ concentration-time profiles were best described by a 2-compartment model (2CM) (Fig. 1). A $2 \mathrm{CM}$ was chosen over other models based on the Akaike Information Criterion (AIC). Goodness-of-fit was assessed by the objective functions and by visual inspection of various diagnostic plots. Furthermore, a 2CM has been commonly used to describe and fit hIgG data in animals (20). The equations for the final two-compartment model (with additional absorption compartment for SC dose) are provided below:

$$
\frac{d A_{c}}{d t}=-\mathrm{CL}_{t} \cdot \frac{A_{c}}{V_{c}}-\mathrm{CL}_{D} \cdot \frac{A_{c}}{V_{c}}+\mathrm{CL}_{D} \cdot \frac{A_{p}}{V_{p}}, \quad \mathrm{IC}=\text { Dose }_{i v}
$$

$$
\frac{d A_{p}}{d t}=\mathrm{CL}_{D} \cdot \frac{A_{c}}{V_{c}}-\mathrm{CL}_{D} \cdot \frac{A_{p}}{V_{p}}, \mathrm{IC}=0
$$

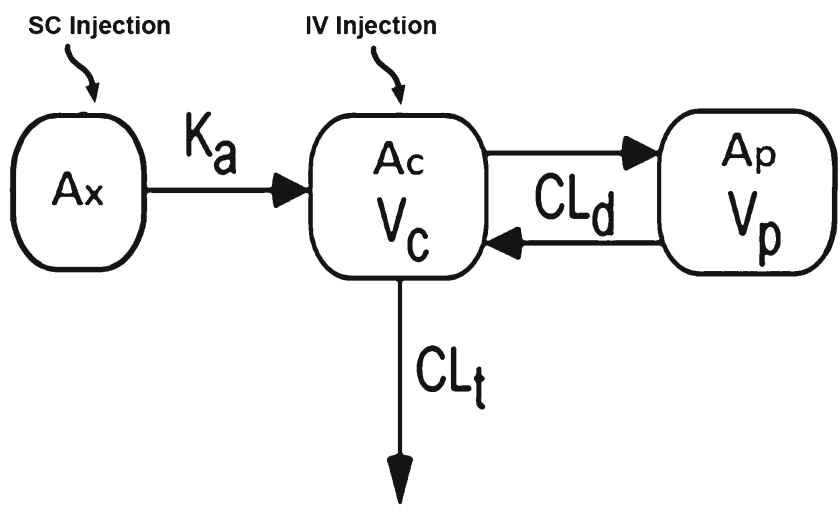

Fig. 1. A schematic representation of the two-compartment pharmacokinetic model for hIgG disposition. Human IgG was dosed IV or SC into the specific compartments. Linear antibody elimination clearance $\left(\mathrm{CL}_{T}\right)$ is assumed to occur solely from the central compartment. Linear distribution clearance $\left(\mathrm{CL}_{\mathrm{d}}\right)$ occurs between the central and peripheral tissue compartments. $V_{\mathrm{c}}$ and $V_{\mathrm{p}}$ represent the volumes of distribution of the central and peripheral tissue compartments, respectively. $A_{\mathrm{x}}$ is the amount of $\mathrm{hIgG}$ at the absorption site while $A_{\mathrm{c}}$ and $A_{\mathrm{p}}$ are the amounts in central and peripheral compartments, respectively $\frac{d A_{x}}{d t}=-k_{a} A_{x}, \mathrm{IC}=$ Dose $_{\mathrm{SC}}$

$\frac{d A_{c}}{d t}=F \cdot k_{a} A_{x}-\mathrm{CL}_{t} \cdot \frac{A_{c}}{V_{c}}-\mathrm{CL}_{D} \cdot \frac{A_{c}}{V_{c}}+\mathrm{CL}_{D} \cdot \frac{A_{p}}{V_{p}}, \mathrm{IC}=0$

$\frac{d A_{p}}{d t}=\mathrm{CL}_{D} \cdot \frac{A_{c}}{V_{c}}-\mathrm{CL}_{D} \cdot \frac{A_{p}}{V_{p}}, \mathrm{IC}=0$

where $\mathrm{CL}_{t}$ is the $\mathrm{hIgG}$ elimination clearance (assumed to occur solely from the central compartment), $\mathrm{CL}_{D}$ is the distribution clearance (that occurs between the central and peripheral tissue compartments), $V_{\mathrm{c}}$ and $V_{\mathrm{p}}$ represent the volumes of distribution of the central and peripheral tissue compartments, respectively. $A_{\mathrm{x}}$ is the amount of $\mathrm{hIgG}$ at the absorption site while $A_{\mathrm{c}}$ and $A_{\mathrm{p}}$ are the amounts in the central and peripheral compartments, respectively. IC represents the initial condition.

Noncompartmental analysis was initially performed using WinNonlin 5.0 (Pharsight Corporation) to determine the initial estimates. Model fittings were performed by nonlinear regression analysis using the maximum likelihood algorithm in ADAPT 5. All PK data was naïve pooled before analysis. In the model setup, $V_{\mathrm{c}}$ and $\mathrm{CL}_{\mathrm{d}}$ were modeled to be same for all the three groups, in phases A and B simultaneously. Different models were created with individual $V_{\mathrm{c}}$ and/or $\mathrm{CL}_{\mathrm{d}}$ and the models were compared among each other (data not shown) based on AIC and goodness-of-fit (objective functions and visual inspection of various diagnostic plots). Based on these parameters, simultaneous fitting of $V_{\mathrm{c}}$ and $\mathrm{CL}_{\mathrm{d}}$ was found to be the most appropriate. Furthermore, under linear conditions, hIgG is primarily distributed into the central plasma compartment and the extravascular fluid (21), thus physiologically, $V_{\mathrm{c}}$ would be constant among all the animal groups. Similarly, $\mathrm{CL}_{\mathrm{d}}$ should not be affected by disease or the treatment. All the other model parameters were either fitted or fixed. Renal clearance was calculated as urinary amount 0 - $t$ $\mathrm{AUC}_{0-\mathrm{t}}$, where $t$ represented at least five half-lives.

\section{Statistical Analysis}

Statistical significance was determined by one-way analysis of variance (ANOVA) with Tukey's test for post hoc analysis, using the GraphPad Prism 5 software. $P$ values $<0.05$ were considered statistically significant.

\section{RESULTS}

\section{Diabetic Study}

\section{Body Weight and Blood Glucose Levels}

Significantly higher blood glucose concentrations were observed in the diabetic group at around 13 weeks of age (phase A, Fig. 2a), demonstrating diabetic progression in this group, and lack of disease in the lean control group. The pioglitazone-treated ZDF diabetic rats had significantly decreased blood glucose levels, similar to the non-diabetic 
a

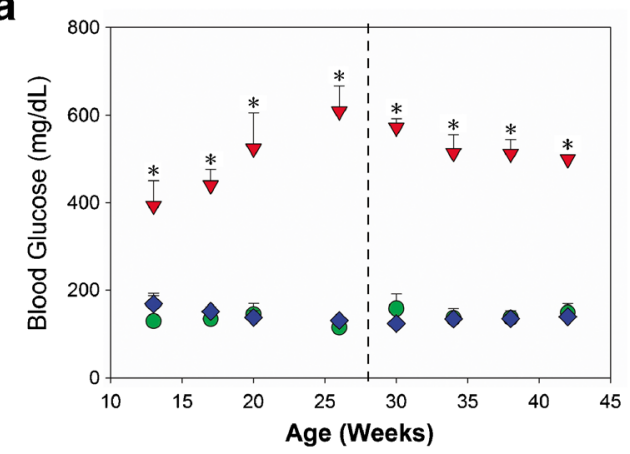

C

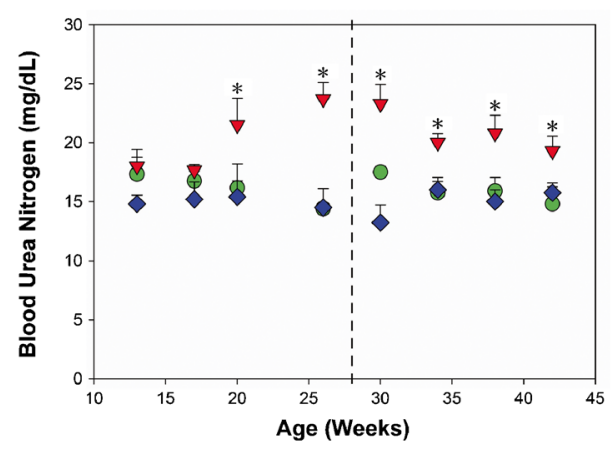

e

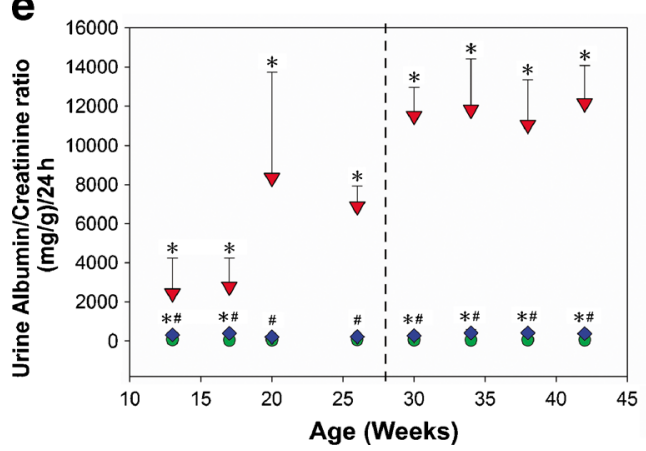

b

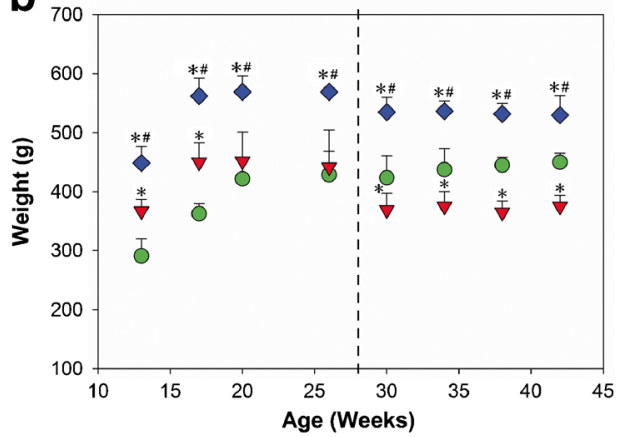

d

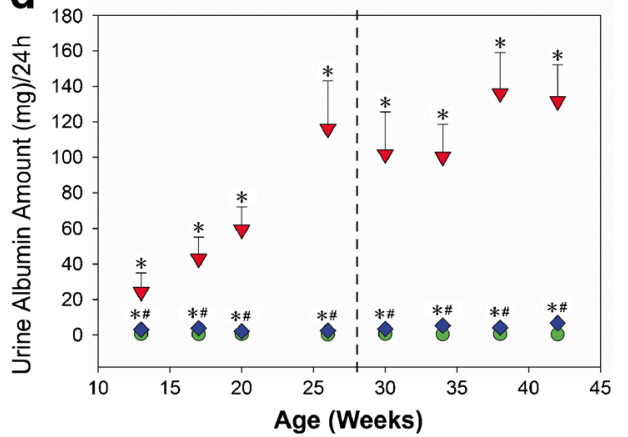

Fig. 2. Profiles for blood glucose (a), weight (b), blood urea nitrogen (c), urinary albumin (d), urinary albumin/creatinine ratios (e) of control (green circles), diabetic (red triangles), and pioglitazone-treated (blue diamonds) ZDF rats. Statistical analysis was performed by one-way ANOVA followed by Tukey's test. Results presented as means \pm SD $(n=6-8)$. Dashed line separates phase A from phase B

control group, and the blood glucose levels were significantly lower than the diabetic group throughout the study. At 13 weeks of age, ZDF diabetic rats exhibited significantly greater body weight than the non-diabetic control rats (Fig. 2b). However, at 29-30 weeks (phase B), the diabetic rats exhibited decreased body weight compared to the non-diabetic control rats. Pioglitazone-treated rats weighed significantly more than the diabetic and non-diabetic rats. An increase in body weight is a known side-effect of pioglitazone treatment (15). The weight gain occurred despite the fact that the pioglitazone-treated rats were pair fed with the diabetic rats.

\section{Kidney Function}

All three groups of animals had similar BUN levels during phase A of the study (Fig. 2c). However, after 17 weeks of age, the diabetic rats had significantly elevated BUN levels as compared to the non-diabetic rats and pioglitazone-treated ZDF diabetic rats. This trend remained constant throughout the study. ZDF diabetic rats had significantly higher ACR and urinary albumin concentrations (Fig. 2d, e, respectively). These values rose consistently with age until 30 weeks of age. The trends associated with ACR and urinary albumin is similar to those reported in the literature for ZDF rats (15). The increasing concentrations of urinary albumin demonstrate diabetic disease progression along with compromised renal function. The pioglitazone-treated rats had significantly lower ACR and urinary albumin amounts than the diabetic rats, but still significantly higher values than the non-diabetic rats.

\section{Pharmacokinetic Studies}

After IV and SC dosing of $1 \mathrm{mg} / \mathrm{kg}$ hIgG, plasma samples were collected for four to five half-lives and analyzed using 
ELISA. Analysis of the mean hIgG concentrations was done by fitting the data to the two-compartmental model (Fig. 1). Model fittings of the PK profiles are presented (phase A, Fig. 3a; phase B, Fig. 3b) and parameter estimates are shown in Tables I and II. Almost complete bioavailability was observed for all the groups in both the phases. Renal clearance and total clearance of hIgG increased significantly ( $\sim 100$-fold and $\sim 2.5$-fold, respectively) in the diabetic animals, and these differences were more pronounced in phase B when the disease had significantly progressed. With pioglitazone treatment in phases $\mathrm{A}$ and $\mathrm{B}$, both the total and renal clearances significantly decreased, but the clearance values were still significantly higher than the non-diabetic control rats. The estimated peripheral volume of distribution was significantly lower is the diabetic rats compared with the control rats. After SC administration, the rate constant for absorption $\left(k_{\mathrm{a}}\right)$ was similar among the three groups in phase A (Table I). However, in phase B, the pioglitazone-treated rats had a significantly decreased value for $k_{\mathrm{a}}$ compared with the diabetic rats (Table II).

\section{Linear Pharmacokinetics in ZDF Rats}

Since the plasma concentrations of hIgG obtained after the SC dose were about twofold lower than after the IV dose, it was necessary to assess whether hIgG followed linear kinetics over this plasma concentration range. The PK parameters of $\mathrm{hIgG}$ following the administration of a lower dose $(0.2 \mathrm{mg} / \mathrm{kg} \mathrm{IV})$ determined in ZDF control and diabetic rats (age 13 weeks) were similar to that after the higher $1 \mathrm{mg} / \mathrm{kg}$ dose; the dose-normalized concentrations were similar for both the doses (Fig. 4). These findings suggest that $\mathrm{hIgG}$ exhibits linear PK over the plasma concentration range observed after IV and SC administration in this study.
Table I. PK Parameters for Human IgG (hIgG) After IV and SC Administration to ZDF Non-diabetic Control, Diabetic and Pioglitazone-Treated Diabetic Rats (Phase A; 12-13 Weeks of Age)

\begin{tabular}{|c|c|c|c|}
\hline \multirow[b]{2}{*}{$\begin{array}{l}\text { Parameter } \\
\text { (units) }\end{array}$} & \multicolumn{3}{|c|}{ Phase A Estimates (\%CV) } \\
\hline & Control & $\begin{array}{l}\text { Pioglitazone- } \\
\text { treated }\end{array}$ & Diabetic \\
\hline$V_{\mathrm{c}}(\mathrm{mL} / \mathrm{kg})^{a}$ & $53.2(8.28)$ & $53.2(8.28)$ & $53.2(8.28)$ \\
\hline$V_{\mathrm{p}}(\mathrm{mL} / \mathrm{kg})$ & $96.7(11.8)$ & $111(10.0)^{\#}$ & $46.2(10.3)^{*}$ \\
\hline $\mathrm{CL}_{\mathrm{d}}(\mathrm{mL} / \mathrm{d} / \mathrm{kg})^{a}$ & $12.9(9.43)$ & $12.9(9.43)$ & $12.9(9.43)$ \\
\hline $\mathrm{CL}_{\mathrm{T}}(\mathrm{mL} / \mathrm{d} / \mathrm{kg})$ & $5.83(6.38)$ & $5.89(8.15)$ & $13.1(4.25)^{*}$ \\
\hline$k_{\mathrm{a}}(1 / \mathrm{d})$ & $0.0982(11.8)$ & $0.113(11.6)$ & $0.116(5.23)$ \\
\hline$F$ & $0.924(6.78)$ & $1.00(6.42)$ & $0.808(5.95)$ \\
\hline$t_{1 / 2}(\mathrm{~d})^{b}$ & 17.6 & 8.69 & 5.29 \\
\hline $\mathrm{CL}_{\mathrm{R}}(\mathrm{mL} / \mathrm{d})^{c}$ & $\begin{array}{l}9.47 \mathrm{E}-03 \\
( \pm 5.72 \mathrm{E}-03)\end{array}$ & $\begin{array}{l}2.30 \mathrm{E}-01 \\
( \pm 8.43 \mathrm{E}-02)\end{array}$ & $\begin{array}{l}1.07 \\
( \pm 3.02 \mathrm{E}-01)\end{array}$ \\
\hline
\end{tabular}

$V_{c}$ volume (central) of distribution, $V_{p}$ volume (peripheral) of distribution, $C L_{T}$ total clearance, $C L_{d}$ distribution clearance, $k_{a}$ rate constant for absorption, $F$ bioavailability

${ }^{a} V_{\mathrm{c}}$ and $\mathrm{CL}_{\mathrm{d}}$ were modeled to be same for all the three groups, in phases $\mathrm{A}$ and $\mathrm{B}$ simultaneously

${ }^{b} t_{1 / 2}$ was calculated as $(0.693) /\left(\mathrm{CL}_{\mathrm{t}} / V_{\mathrm{c}}+V_{\mathrm{p}}\right)$

${ }^{c} \mathrm{CL}_{\mathrm{R}}=$ renal clearance was calculated as urinary amount ${ }_{0-\mathrm{t}} / \mathrm{AUC}_{0-\mathrm{t}}$ where $t=5$ half-lives of $\mathrm{hIgG}$, presented as mean \pm SD.

* Statistically significant from control group

\# Statistically significant from diabetic group at $P \leq 0.05$ [one-way ANOVA with Tukey's test]; $(n=6-8)$

\section{Endogenous Rat IgG in ZDF Rats}

Plasma concentrations and urinary excretion amounts of endogenous $\mathrm{rgG}$ were determined in order to evaluate the disposition of endogenous $\mathrm{rgG}$ in the non-diabetic control and diabetic rats. The steady-state plasma concentrations of rat IgG were similar for both groups (Table III). On the other hand, the urinary excretion of $\operatorname{IgG}$ between the two groups
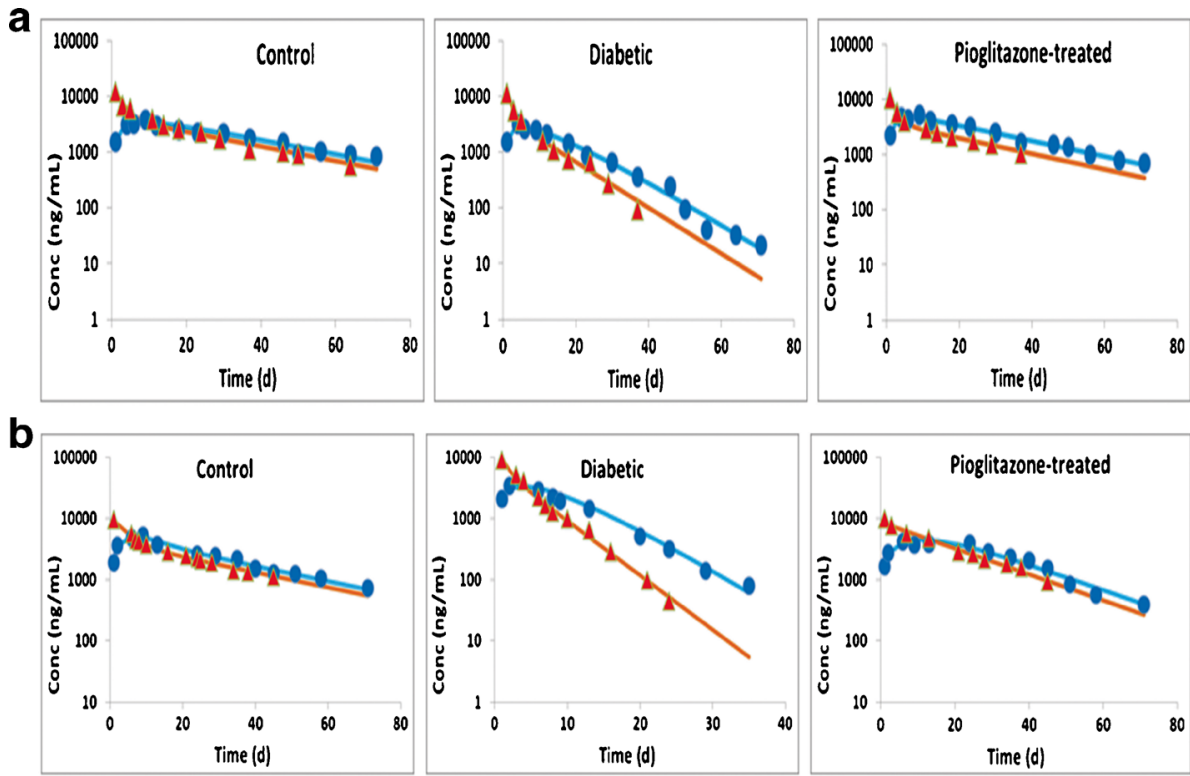

Fig. 3. Plasma concentrations of human $\operatorname{IgG}(\mathrm{hIgG})$ after IV (red triangles) and SC (blue circles) administration to ZDF diabetic, non-diabetic control rats and pioglitazone-treated ZDF diabetic rats (a phase A, age 12-13 weeks; $n=6-8$; and b Phase B, age 29-30 weeks; $n=6-8$ ). Symbols represent data collected and lines represent model fittings. Data presented as mean $\pm \mathrm{SD}$ 
Table II. PK Parameters for Human IgG (hIgG) After IV and SC Administration to ZDF Non-diabetic Control, Diabetic and Pioglitazone-treated Diabetic Rats (Phase B; 29-30 Weeks of Age)

\begin{tabular}{|c|c|c|c|}
\hline \multirow[b]{2}{*}{$\begin{array}{l}\text { Parameter } \\
\text { (Units) }\end{array}$} & \multicolumn{3}{|c|}{ Phase B Estimates (\%CV) } \\
\hline & Control & $\begin{array}{l}\text { Pioglitazone- } \\
\text { treated }\end{array}$ & Diabetic \\
\hline$V_{\mathrm{c}}(\mathrm{mL} / \mathrm{kg})^{a}$ & $53.2(8.28)$ & $53.2(8.28)$ & $53.2(8.28)$ \\
\hline$V_{\mathrm{p}}(\mathrm{mL} / \mathrm{kg})$ & $98.7(9.59)$ & $95.7(11.0){ }^{\#}$ & $26.8(9.99)^{*}$ \\
\hline $\mathrm{CL}_{\mathrm{d}}(\mathrm{mL} / \mathrm{d} / \mathrm{kg})^{a}$ & $12.9(9.43)$ & $12.9(9.43)$ & $12.9(9.43)$ \\
\hline $\mathrm{CL}_{\mathrm{T}}(\mathrm{mL} / \mathrm{d} / \mathrm{kg})$ & $5.63(7.80)$ & $6.85(5.51)^{\#}$ & $20.9(4.80)^{*}$ \\
\hline$k_{\mathrm{a}}(1 / \mathrm{d})$ & $0.136(11.5)$ & $0.107(13.0)^{\#}$ & $0.167(4.13)^{*}$ \\
\hline$F$ & $0.998(5.72)$ & $0.849(6.79)$ & $0.879(6.24)$ \\
\hline$t_{1 / 2}(\mathrm{~d})^{b}$ & 18.7 & 15.1 & 2.65 \\
\hline $\mathrm{CL}_{\mathrm{R}}(\mathrm{mL} / \mathrm{d})^{c}$ & $\begin{array}{l}1.11 \mathrm{E}-02 \\
( \pm 6.49 \mathrm{E}-03)\end{array}$ & $\begin{array}{l}3.83 \mathrm{E}-01 \\
\quad( \pm 1.01 \mathrm{E}-01)\end{array}$ & $\begin{array}{l}3.07 \\
( \pm 2.75 \mathrm{E}-01)\end{array}$ \\
\hline
\end{tabular}

$V_{c}$ volume (central) of distribution, $V_{p}$ volume (peripheral) of distribution, $C L_{T}$ total clearance, $C L_{d}$ distribution clearance, $k_{a}$ rate constant for absorption, $F$ bioavailability

${ }^{a} V_{\mathrm{c}}$ and $\mathrm{CL}_{\mathrm{d}}$ were modeled to be same for all the three groups, in phases A and B simultaneously

${ }^{b} t_{1 / 2}$ was calculated as $(0.693) /\left(\mathrm{CL}_{\mathrm{t}} / V_{\mathrm{c}}+V_{\mathrm{p}}\right)$

${ }^{c} \mathrm{CL}_{\mathrm{R}}=$ renal clearance was calculated as urinary amount $\mathrm{ot}_{0-\mathrm{t}} / \mathrm{AUC}_{0-\mathrm{t}}$ where $t=5$ half-lives of $\mathrm{hIgG}$, presented as mean \pm SD.

*Statistically significant from control group

\# Statistically significant from diabetic group at $P \leq 0.05$ [one-way ANOVA with Tukey's test]; $(n=6-8)$

a

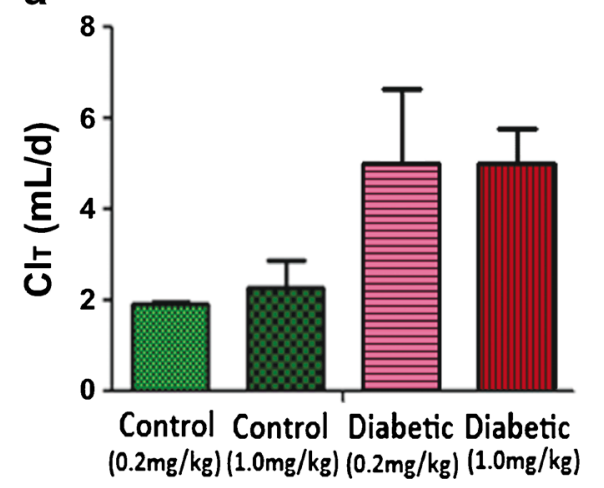

C

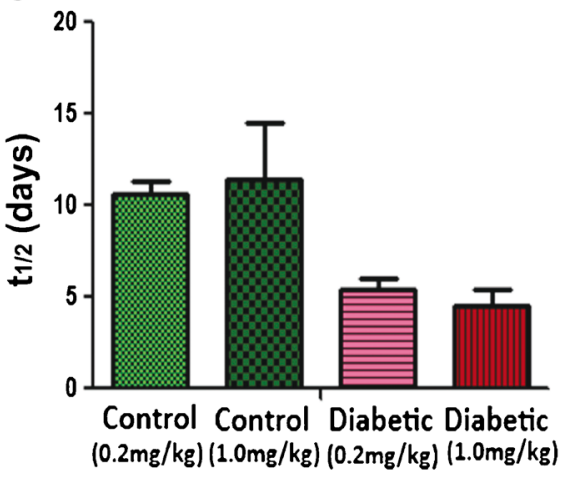

Table III. Comparison of Changes in Rat Endogenous IgG (rIgG) Plasma Concentrations $(\mathrm{mg} / \mathrm{mL})$ with Age, in Control and Diabetic Groups (Mean $\pm \mathrm{SD} ; n=4)$

\begin{tabular}{lll}
\hline & Rat endogenous IgG plasma concentrations $(\mathrm{mg} / \mathrm{mL})$ \\
\hline Week & Control & Diabetic \\
\hline 13 & $5.15(2.17)$ & $4.49(0.713)$ \\
17 & $6.54(2.88)$ & $5.32(0.615)$ \\
20 & $5.02(1.35)$ & $5.09(1.21)$ \\
24 & $5.14(0.674)$ & $4.92(1.38)$ \\
30 & $5.78(2.03)$ & $4.53(1.62)$ \\
34 & $6.95(2.79)$ & $5.70(1.54)$ \\
38 & $5.03(0.909)$ & $5.71(1.56)$ \\
\hline
\end{tabular}

was similar to that seen with albumin and hIgG (Fig. 5). Although the urinary amounts were significantly different between the two groups, they were less than $1 \%$ of the estimated rat endogenous $\mathrm{IgG}$ amounts, resulting in no change in the observed plasma concentration.

\section{CKD Study}

Body Weight

The weight of both the sham control and the 5/6 nephrectomized rats were similar throughout the study (Fig. 6a).

b

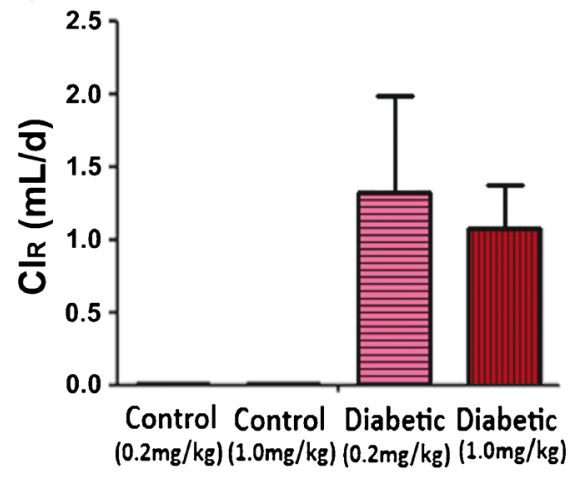

d

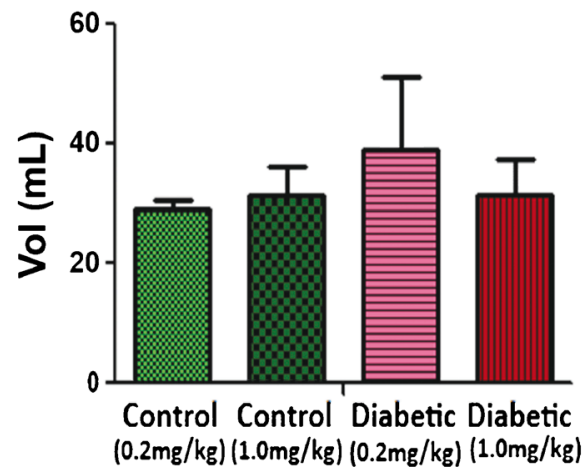

Fig. 4. Comparison of the pharmacokinetic parameters for 0.2 and $1 \mathrm{mg} / \mathrm{kg}$ human $\mathrm{IgG}$ (hIgG) doses. Parameters were determined by noncompartmental analysis using WinNonlin 5.0 (Pharsight Corporation). Statistical analysis was performed using Student's $t$ test (mean $\pm \mathrm{SD} ; n=4$ ) 


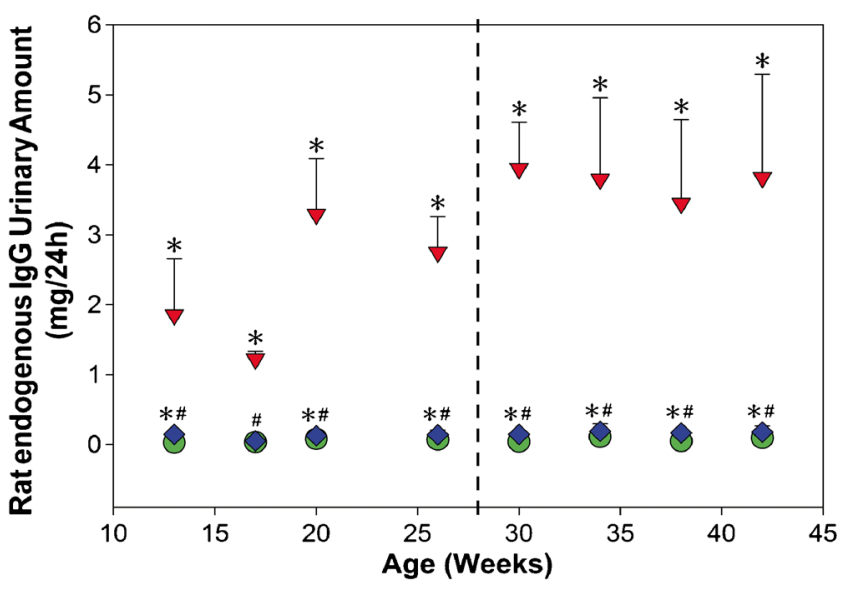

Fig. 5. Comparison of changes in rat endogenous $\operatorname{IgG}(\mathrm{rIgG})$ urinary amounts with age in control (green circles), diabetic (red triangles), and pioglitazone-treated diabetic (blue diamonds) groups *Statistically significant from control group. ${ }^{\#}$ Statistically significant from diabetic group at $P<0.05$ [One-way ANOVA with Tukey's Test]; $($ mean $\pm \mathrm{SD} ; n=4)$. Dashed line separates phase A from phase B

\section{Kidney Function}

BUN, ACR, and urinary albumin concentrations for the $5 / 6$ nephrectomized rats were significantly higher, compared to the control animals, and remained higher throughout the study (Fig. 6b-d, respectively).

\section{Pharmacokinetic Study}

Analysis of the mean plasma hIgG concentration was done by fitting the data to a two-compartmental model (Fig. 1). Parameter estimates are shown in Table IV. Following IV as well as SC dosing, there was no difference in the parameter estimates of total clearance and volume of distribution between control and 5/6 nephrectomized rats. However, the renal clearance of hIgG in $5 / 6$ nephrectomized rats was significantly greater as compared to the control rats.

\section{DISCUSSION}

Approximately 25 million Americans have been diagnosed with T2DM and approximately 26 million with CKD $(22,23)$. Considering the high incidence rate of these diseases ( $\sim 10 \%$ of the American population), and their high association with co-morbidities (heart disease, retinopathy, neuropathy), the use of mAbs in these populations is increasing (2426). There is little published literature evaluating the effects of DM on antibody PK; however, considering the physiologic changes in this disease, potential effects on PK are likely, even in the absence of renal dysfunction. One of the primary complications of DM is an alteration in the vasculature and renal function, leading to the many long-term manifestations associated with this disease (25). Although urinary excretion is not a significant route of $\mathrm{mAb}$ elimination in healthy subjects, renal excretion of therapeutic mAbs may occur, as it does for endogenous proteins in DM, leading to increased a

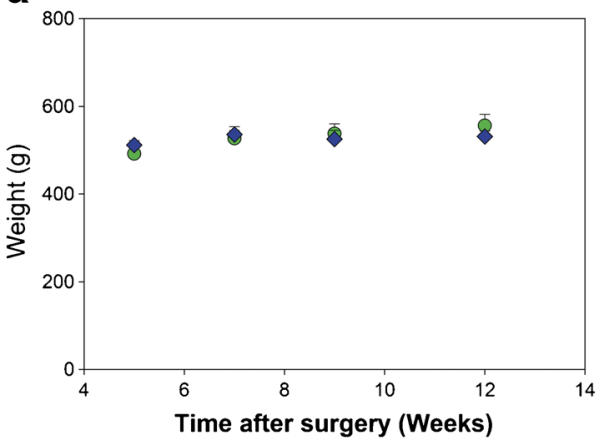

C

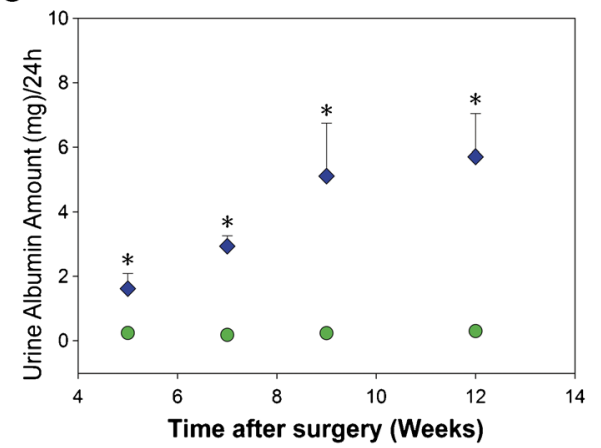

b

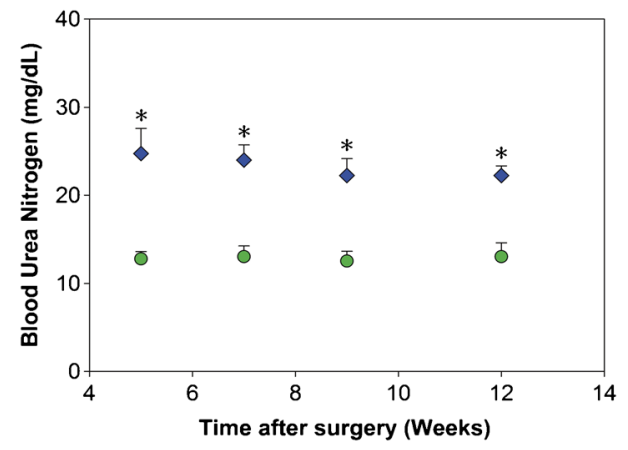

d

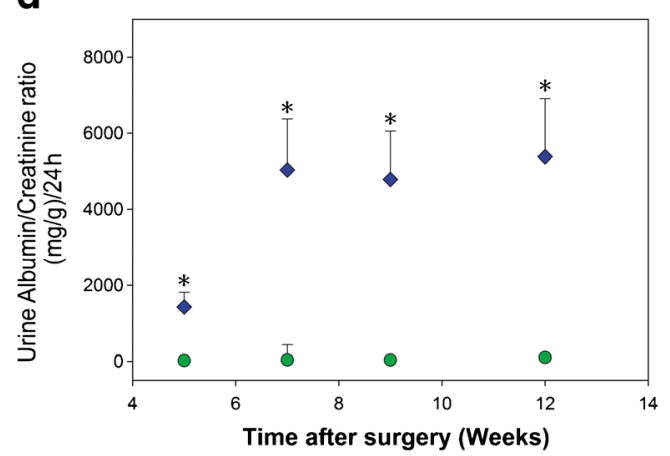

Fig. 6. Profiles for weight (a), blood urea nitrogen (b), urinary albumin (c), and urinary albumin/creatinine ratios (d) of control (green circles) and 5/6 nephrectomized rats (blue diamonds). *Statistically significant from control group at $P<0.05$ [Student's $t$ test]; (mean $\pm \mathrm{SD} ; n=4)$ 
Table IV. PK Parameters for Human IgG (hIgG) after IV and SC Administration to Control and 5/6 Nephrectomized Rats

\begin{tabular}{|c|c|c|}
\hline \multirow[b]{2}{*}{ Parameter (Units) } & \multicolumn{2}{|c|}{ Estimates (\% CV) } \\
\hline & Control & 5/6 Nephrectomized \\
\hline $\mathrm{CL}_{\mathrm{T}}(\mathrm{mL} / \mathrm{d} / \mathrm{kg})$ & $4.37(1.74)$ & $3.86(3.10)$ \\
\hline$V_{\mathrm{c}}(\mathrm{mL} / \mathrm{kg})$ & $37.0(6.74)$ & $39.3(19.2)$ \\
\hline $\mathrm{CL}_{\mathrm{d}}(\mathrm{mL} / \mathrm{d} / \mathrm{kg})$ & $13.7(15.8)$ & $11.3(24.0)$ \\
\hline$V_{\mathrm{p}}(\mathrm{mL} / \mathrm{kg})$ & $32.4(5.77)$ & $32.6(16.4)$ \\
\hline$k_{\mathrm{a}}(1 / \mathrm{d})$ & $0.723(27.1)$ & $1.06(27.0)$ \\
\hline$F$ & $0.660(6.25)$ & $0.743(4.15)$ \\
\hline$t_{1 / 2}(\mathrm{~d})^{a}$ & 11.0 & 12.9 \\
\hline $\mathrm{CL}_{\mathrm{R}}(\mathrm{mL} / \mathrm{d})^{b}$ & $1.86 \mathrm{E}-02( \pm 3.85 \mathrm{E}-03)$ & $5.60 \mathrm{E}-02 *( \pm 2.75 \mathrm{E}-02)$ \\
\hline
\end{tabular}

${ }^{a} t_{1 / 2}$ was calculated as $(0.693) /\left(\mathrm{Cl}_{\mathrm{t}} / V_{\mathrm{c}}+V_{\mathrm{p}}\right)$

${ }^{b} \mathrm{Cl}_{\mathrm{R}}=$ renal clearance was calculated as urinary amount ${ }_{0-\mathrm{t}} / \mathrm{AUC}_{0-\mathrm{t}}$ ) where $t=5$ half-lives of $\mathrm{hIgG}$, presented as mean \pm SD.

*Statistically significant from control group at $p \leq 0.05$ [Student's $t$ test]; $(n=4)$

mAb clearance. Micro- and macroalbuminuria are common in diabetes and renal diseases, and a limited number of studies have reported the increased renal elimination and urinary concentrations of $\operatorname{IgG}$ with DM/DN $(9,10)$.

It is known that moderate CKD leads to the urinary excretion of endogenous proteins, such as albumin, that are normally conserved (27). Furthermore, larger proteins, such as $\operatorname{IgG}$ (mol radius $5.5 \mathrm{~nm}$ ) or $\operatorname{IgM}$ (mol radius $12 \mathrm{~nm}$ ) that have limited renal elimination, are known to have higher transport across the glomerular filter with compromised renal function and DN (9). The increased size and density of larger pores, along with increased density of shunts in the glomerular capillary wall, leads to increased concentrations of larger molecules in the urine. Therefore, in patients with moderate $\mathrm{CKD} / \mathrm{DN}$ (with some degree of urinary output), renal excretion of therapeutic mAbs would occur, leading to increased $\mathrm{mAb}$ clearance, compared to that in healthy subjects or in patients with end-stage renal disease.

In the current study, we examined the clearance and SC bioavailability of $\mathrm{hIgG}$, an antibody isotype, in an animal model of type 2 diabetes (Zucker diabetic fatty rats) and in an animal model of chronic renal failure (5/6 nephrectomized rats). Our studies with ZDF diabetic rats have shown that there is significant hyperglycemia at $12-13$ weeks of age, associated with microalbuminuria and no change in BUN; at 28-30 weeks of age there is decreased renal function as demonstrated by macroalbuminuria and increased BUN. Therefore, we can distinguish between the effects due to $\mathrm{DM}$, and those associated with DM/DN by studying adult animals at different ages (i.e., phases $\mathrm{A}$ and $\mathrm{B}$, respectively). We observed a significant difference in the clearance of hIgG in $\mathrm{ZDF}$ rats, compared to control animals, in the initial hyperglycemic phase, as well as with onset of DN. The total clearance in diabetic animals increased by 2.5- and 3.5-fold (phases $\mathrm{A}$ and $\mathrm{B}$, respectively), while the renal clearance increased by 100 -and 300 -fold, respectively. Although increases in the renal clearance were highly significant, the overall increase represented only a small portion $(14.5 \%$ in phase $\mathrm{A}$ and $20.1 \%$ in phase B) of the observed changes in total clearance. Therefore, our studies demonstrate significant changes in the non-renal clearance of $\mathrm{hIgG}$, in addition to the changes in renal clearance. The 2CM estimated significantly lower peripheral volume for diabetic animals ( $\sim 2$-fold in phase $\mathrm{A}$ and 4-fold in phase B). On the other hand, the $V_{\mathrm{p}}$ was similar for control and pioglitazone-treated animals. Although a $2 \mathrm{CM}$ estimates $V_{\mathrm{c}}$ and $\mathrm{CL}_{\mathrm{t}}$ similar to physiologically relevant volumes (28), there is the assumption that the clearance is only from the central compartment. Thus, $V_{\mathrm{p}}$ values are limited in identifiability, and as such the significance of $V_{\mathrm{p}}$ changes may not be physiologically relevant (29).

With pioglitazone treatment, we have observed that there is reversal of the hyperglycemia (glucose levels become similar to the non-diabetic control rats), resulting in a pronounced reduction in the total and renal clearances of $\mathrm{hIgG}$; these studies suggest the significance of hyperglycemia and effects related to the hyperglycemia in the alterations in clearance of hIgG. However, the renal and total clearances following pioglitazone treatment were still slightly but significantly higher than the non-diabetic control rats. This trend was also observed with the urinary excretion of albumin and endogenous $\mathrm{rIgG}$ where pioglitazone treatment showed a significant but incomplete reversal of the diabetic-induced changes in the renal and total clearance of these endogenous proteins.

Studies were performed to distinguish the effects of DM and DN from those associated with CKD. The $5 / 6$ nephrectomized Sprague Dawley rat model mimics the progressive renal failure after loss of renal mass (19). Animals develop proteinuria and early glomerular hypertrophy during the acute phase (after 4 weeks), with increases in BUN. These rats demonstrated significantly altered renal biomarkers including increased BUN, urinary albumin amounts, and ACR in this study. These changes in renal function were accompanied by an increase in the renal clearance of hIgG; however, there was no effect on the plasma concentrations and total clearance of hIgG, compared with sham controls. Overall, the findings of this study, along with those of the pioglitazone treatment study, suggest that hyperglycemia and other changes directly related to diabetes may play a role in the increased clearance of $\mathrm{hIgG}$ observed in the ZDF rats. However, there were some differences in renal function between the 5/6 nephrectomized rats and our ZDF rats studied at ages of 26 weeks and higher (when they exhibited DN). Although BUN was similar between both groups of animals, the urinary albumin excretion and ACR was five- to tenfold lower for the 5/6 nephrectomized rats. Whether the differences in urinary albumin excretion are directly related to diabetes, or reflect characteristics of the rat strain or animal disease models are unknown.

The mechanisms underlying the changes in renal and non-renal clearance of $\mathrm{IgG}$ in diabetes are currently unknown. One potential mechanism that may alter clearance is the increased glycosylation of IgG. Chronic hyperglycemia in DM leads to non-enzymatic glycation of proteins or advanced protein glycosylation. This process involves the nonenzymatic modification of proteins by physiologic sugars and plays a significant role in the pathogenesis of diabetic complications (30). Hemoglobin undergoes glycosylation during early phases of DM. Other proteins too undergo this process in DM and studies have shown $\operatorname{IgG}, \operatorname{IgM}, \operatorname{IgA}$, and albumin to undergo glycosylation. A positive correlation has been observed between glycosylated hemoglobin and 
glycosylated $\operatorname{IgG}(31,32)$. Significantly increased vascular clearance rate of glycated $\mathrm{IgG}$, compared to unglycated $\mathrm{IgG}$, has been reported (33). Many other studies have observed glycation to cause structural and functional changes in $\mathrm{IgG}$, such as decreasing the ability of $\mathrm{IgG}$ to fix complement and impairing binding to Protein A $(34,35)$. Cross-linking of proteins also occurs, which leads to the formation of advanced glycosylation end-products (AGE). Macrophages possess receptors with a high affinity for AGEproteins, and thus lead to high non-renal clearance of these proteins $(33,36)$. Furthermore, glycosylation also plays an important role in glomerular basement membrane (GBM) and podocyte damage, during progression to diabetic nephropathy (37).

Alterations in the neonatal $\mathrm{Fc}$ receptor $(\mathrm{FcRn})$, that plays a pivotal role for the recycling and clearance of antibodies, may contribute to the increases in the renal and non-renal clearances of $\mathrm{IgG}$ (38). FcRn is present in liver, spleen, kidney, intestine, endothelial cells, skin, muscle, and adipose tissue and is known to be very important in the catabolism of IgG and antibodies $(39,40)$. Moreover, hypercatabolism of $\mathrm{IgG}$ has been observed in mice with lupus-like syndrome, by disease-induced impairment of FcRn function (41). FcRn expression in intestinal epithelial cells, macrophage-like THP-1, and primary human monocytes can be induced by inflammatory markers such as TNF- $\alpha$ and IL$1 \beta$ (42). Additionally, biodistribution studies with FcRn knockout animals have reported altered PK and distribution of IgG. (40). Changes in the expression of other transcytosis proteins including megalin/cubilin may also contribute to the changes in renal and non-renal clearance of proteins. Megalin and cubilin are multi-ligand, endocytic receptors with significant physiological functions. These are co-expressed in several absorptive epithelia, small intestine and renal proximal tubule. Megalin is more widely distributed than cubilin and is expressed in glomerular podocytes as well (43). Megalin and cubilin function together in the reabsorption of proteins, including $\operatorname{IgG}$ and albumin, in the proximal tubule $(43,44)$. Impairment of megalin function in diabetes has been suggested, even in the early stages of diabetes in animal models and in patients (45). Megalin expression can be severely downregulated due to protein over-load in diabetes, via activation of the renin-angiotensin system and increased TGF- $\beta$ and TNF- $\alpha$ signaling in the lumen of the proximal tubular cells (46). Pioglitazone at low doses, even without glycemic control, normalizes the renal levels of TNF- $\alpha$ and megalin (47). Thus, impaired renal expression of megalin may not only inhibit the clearance of $\mathrm{IgG}$ antibodies from glomerular podocytes (thus causing local inflammation and glomerular damage), but also prevent the uptake and catabolism of $\mathrm{IgG}$ through the proximal tubule cells (43). During protein overload in diseases like T2DM, these receptors would mediate uptake of surplus protein for accumulation in lysosomes. Thus, megalin and cubilin may be regulated during nephrotic syndrome, either through a decrease in expression to protect the proximal tubule from toxic accumulation or through an increase to fulfill their role as scavenger receptors (48).

Our study also examined the SC bioavailability of hIgG in $\mathrm{DM}$ and $\mathrm{DM} / \mathrm{DN}$. The bioavailability of therapeutic proteins is highly variable $(50 \%-100 \%)$ and not only is it dependent on the species involved, but also on the site of the injection, as well as other determinants (49). We have used the flank region for injecting hIgG in all groups of animals and the bioavailability after SC administration was high $(>84 \%)$ and did not differ among diabetic, pioglitazonetreated diabetic and control animals. However, the absorption rate constant $\left(k_{\mathrm{a}}\right)$ after the SC administration of hIgG was significantly different among the groups in the phase B studies. Whereas the obese pioglitazone-treated animals had a significantly smaller $k_{\mathrm{a}}$, the diabetic animals had greater $k_{\mathrm{a}}$ values compared with the control and the pioglitazonetreated diabetic groups. These $k_{\mathrm{a}}$ values are inversely related to body weight, with the diabetic animals having the lowest body weight and the pioglitazone-treated diabetic rats, the highest body weights. The pioglitazone-treated rats had significantly higher body weight (with a significant increase in subcutaneous and mesenteric fat) compared to both the diabetic and control groups. On the other hand, the diabetic rats lost significant weight during phase $\mathrm{B}$ (with loss of muscle and subcutaneous fat) associated with disease progression. Body weight and body mass index (BMI) are also known to play an important role in SC administration in humans (5052). Obese subjects have lower fasting and post-prandial SC abdominal adipose tissue blood flow and basal adipose tissue blood flow is negatively correlated with BMI (53). Microvascular dysfunction represents an early event in obesity even in the absence of hypertension, hypercholesteremia, and hyperglycemia (54,55). Clinically, obese subjects have lower fasting and post-prandial SC abdominal adipose tissue blood flow and basal adipose tissue blood flow is negatively correlated with BMI (53). Obesity is associated with decreased tissue perfusion due to endothelial dysfunction or decrease in capillary density (56). Adipose tissue blood flow at the SC site has been measured in clinical studies and found to be decreased; additionally, there are decreased capillaries with an increase in adipose tissue $(53,55)$. Although the mechanism underlying the correlation between obesity and absorption cannot be determined in this study, based on the literature and our present results, obesity may be playing a role in the changes observed in the rate of SC absorption of $\mathrm{hIgG}$ in the present studies.

\section{CONCLUSIONS}

Overall, our studies demonstrate that diabetes significantly impacts the renal and total clearance of hIgG in the ZDF type 2 diabetic animal model. While renal clearance of $\mathrm{hIgG}$ is increased by 100 - to 300 -fold, the major change is an increase in non-renal clearance. With pioglitazone treatment, the effects of diabetes on the PK of hIgG were significantly reversed. However, the pioglitazone-treated diabetic animals still demonstrated slightly, but significantly, elevated total and renal clearances. Changes in renal and total clearances were greater in the diabetic animals 29-30 weeks of age, with the progression to diabetic nephropathy. No changes in the clearance of hIgG were observed with 5/6 nephrectomized rats. Our studies suggest that there may be increased clearance of monoclonal antibodies in poorly controlled diabetic subjects that demonstrate hyperglycemia. Future studies are needed to investigate the clinical relevance of 
the current study results and the mechanism(s) underlying potential changes in renal and non-renal clearance of monoclonal antibodies in type 2 diabetes.

\section{ACKNOWLEDGMENTS}

We would like to acknowledge the help of Rashia Kniffen, Rutwij Dave, and Xiao Wen Guan in dosing and collection of samples and Dr. Bridget Morse in grant writing. This study was supported by grants from the Center for Protein Therapeutics, University at Buffalo.

\section{REFERENCES}

1. Guariguata L, Whiting D, Weil C, Unwin N. The International Diabetes Federation diabetes atlas methodology for estimating global and national prevalence of diabetes in adults. Diabetes Res Clin Pract. 2011;94(3):322-32.

2. Wild S, Roglic G, Green A, Sicree R, King H. Global prevalence of diabetes: estimates for the year 2000 and projections for 2030. Diabetes Care. 2004;27(5):1047-53.

3. Ritz E, Orth SR. Nephropathy in patients with type 2 diabetes mellitus. N Engl J Med. 1999;341(15):1127-33.

4. Bakris GL. Recognition, pathogenesis, and treatment of different stages of nephropathy in patients with type 2 diabetes mellitus. Mayo Clin Proc. 2011;86(5):444-56.

5. Gross JL, de Azevedo MJ, Silveiro SP, Canani LH, Caramori ML, Zelmanovitz T. Diabetic nephropathy: diagnosis, prevention, and treatment. Diabetes Care. 2005;28(1):164-76.

6. Scheffel RS, Bortolanza D, Weber CS, Costa LA, Canani LH, Santos KG, et al. Prevalence of micro and macroangiopatic chronic complications and their risk factors in the care of out patients with type 2 diabetes mellitus. Rev Assoc Med Bras. 2004;50(3):263-7. Prevalencia de complicacoes micro e macrovasculares e de seus fatores de risco em pacientes com diabetes melito do tipo $2 \mathrm{em}$ atendimento ambulatorial.

7. Palmer AJ, Valentine WJ, Chen R, Mehin N, Gabriel S, Bregman B, et al. A health economic analysis of screening and optimal treatment of nephropathy in patients with type 2 diabetes and hypertension in the USA. Nephrol Dial Transplant: Off Publ Eur Dial Transplant Assoc Eur Renal Assoc. 2008;23(4):1216-23.

8. Dostalek M, Akhlaghi F, Puzanovova M. Effect of diabetes mellitus on pharmacokinetic and pharmacodynamic properties of drugs. Clin Pharmacokinet. 2012;51(8):481-99.

9. Bakoush O, Tencer J, Tapia J, Rippe B, Torffvit O. Higher urinary IgM excretion in type 2 diabetic nephropathy compared to type 1 diabetic nephropathy. Kidney Int. 2002;61(1):203-8.

10. Lemley KV, Blouch K, Abdullah I, Boothroyd DB, Bennett PH, Myers BD, et al. Glomerular permselectivity at the onset of nephropathy in type 2 diabetes mellitus. J Am Soc Nephro: JASN. 2000;11(11):2095-105.

11. Roberts BV, Susano I, Gipson DS, Trachtman H, Joy MS. Contribution of renal and non-renal clearance on increased total clearance of adalimumab in glomerular disease. J Clin Pharmacol. 2013;53(9):919-24.

12. Mercuri SR, Naldi L. Potential role of ustekinumab in the treatment of chronic plaque psoriasis. Biologics Targets Ther. 2010;4:119-29.

13. Engler FA, Zheng B, Balthasar JP. Investigation of the influence of nephropathy on monoclonal antibody disposition: a pharmacokinetic study in a mouse model of diabetic nephropathy. Pharm Res. 2014;31(5):1185-93.

14. Hamilton RG. Human IgG subclass measurements in the clinical laboratory. Clin Chem. 1987;33(10):1707-25.

15. Hempe J, Elvert R, Schmidts HL, Kramer W, Herling AW. Appropriateness of the Zucker diabetic fatty rat as a model for diabetic microvascular late complications. Lab Anim. 2012;46(1):32-9.

16. Griffen SC, Wang J, German MS. A genetic defect in beta-cell gene expression segregates independently from the fa locus in the ZDF rat. Diabetes. 2001;50(1):63-8.

17. Finegood DT, McArthur MD, Kojwang D, Thomas MJ, Topp BG, Leonard T, et al. Beta-cell mass dynamics in Zucker diabetic fatty rats. Rosiglitazone prevents the rise in net cell death. Diabetes. 2001;50(5):1021-9.

18. Kliem V, Johnson RJ, Alpers CE, Yoshimura A, Couser WG, Koch KM, et al. Mechanisms involved in the pathogenesis of tubulointerstitial fibrosis in 5/6-nephrectomized rats. Kidney Int. 1996;49(3):666-78.

19. Yang HC, Zuo Y, Fogo AB. Models of chronic kidney disease. Drug Discov Today Dis Models. 2010;7(1-2):13-9.

20. Kacskovics I, Kis Z, Mayer B, West Jr AP, Tiangco NE, Tilahun $\mathrm{M}$, et al. FcRn mediates elongated serum half-life of human IgG in cattle. Int Immunol. 2006;18(4):525-36.

21. Tabrizi M, Bornstein GG, Suria H. Biodistribution mechanisms of therapeutic monoclonal antibodies in health and disease. AAPS J. 2010;12(1):33-43.

22. Prevention. CfDCa. National diabetes fact sheet: national estimates and general information on diabetes and prediabetes in the United States. Atlanta, GA: US Department of Health and Human Services, Center for Disease Control and Prevention; 2011.

23. Foundation NK. About chronic kidney disease. 2012; Available from: http://www.kidney.org/kidneydisease/aboutckd.cfm.

24. Boni-Schnetzler M, Donath MY. How biologics targeting the IL1 system are being considered for the treatment of type 2 diabetes. Br J Clin Pharmacol. 2012;76(2):263-8.

25. Cavelti-Weder C, Babians-Brunner A, Keller C, Stahel MA, Kurz-Levin $\mathrm{M}$, Zayed $\mathrm{H}$, et al. Effects of gevokizumab on glycemia and inflammatory markers in type 2 diabetes. Diabetes Care. 2012;35(8):1654-62.

26. Rissanen A, Howard CP, Botha J, Thuren T. Effect of anti-IL-1beta antibody (canakinumab) on insulin secretion rates in impaired glucose tolerance or type 2 diabetes: results of a randomized, placebo-controlled trial. Diabetes Obes Metab. 2012;14(12):1088-96.

27. Eknoyan G, Hostetter T, Bakris GL, Hebert L, Levey AS, Parving $\mathrm{HH}$, et al. Proteinuria and other markers of chronic kidney disease: a position statement of the national kidney foundation (NKF) and the national institute of diabetes and digestive and kidney diseases (NIDDK). Am J Kidney Dis Off J Natl Kidney Found. 2003;42(4):617-22.

28. Wu F, Tamhane M, Morris ME. Pharmacokinetics, lymph node uptake, and mechanistic PK model of near-infrared dye-labeled bevacizumab after IV and SC administration in mice. AAPS J. 2012;14(2):252-61.

29. Cao Y, Balthasar JP, Jusko WJ. Second-generation minimal physiologically-based pharmacokinetic model for monoclonal antibodies. J Pharmacokinet Pharmacodyn. 2013;40(5):597-607.

30. Brownlee M. Advanced protein glycosylation in diabetes and aging. Annu Rev Med. 1995;46:223-34.

31. Kalia K, Sharma S, Mistry K. Non-enzymatic glycosylation of immunoglobulins in diabetic nephropathy. Clin Chim Acta. 2004;347(1-2):169-76.

32. Mistry K, Kalia K. Non enzymatic glycosylation of $\mathrm{IgG}$ and their urinary excretion in patients with diabetic nephropathy. Indian $\mathbf{J}$ Clin Biochem: IJCB. 2009;24(2):159-65.

33. Kennedy DM, Skillen AW, Self CH. Glycation increases the vascular clearance rate of IgG in mice. Clin Exp Immunol. 1993;94(3):447-51.

34. Dolhofer R, Siess EA, Wieland OH. Nonenzymatic glycation of immunoglobulins leads to an impairment of immunoreactivity. Biol Chem Hoppe Seyler. 1985;366(4):361-6.

35. Dolhofer-Bliesener R, Gerbitz KD. Impairment by glycation of immunoglobulin G Fc fragment function. Scand J Clin Lab Invest. 1990;50(7):739-46.

36. Vlassara H, Brownlee M, Cerami A. High-affinity-receptormediated uptake and degradation of glucose-modified proteins: a potential mechanism for the removal of senescent macromolecules. Proc Natl Acad Sci U S A. 1985;82(17):5588-92.

37. Mohan S, Kalia K, Mannari J. Association between urinary IgG and relative risk for factors affecting proteinuria in type 2 diabetic patients. Indian J Clin Biochem: IJCB. 2012;27(4):333-9. 
38. Brambell FW, Hemmings WA, Morris IG. A theoretical model of gamma-globulin catabolism. Nature. 1964;203:1352-4.

39. Borvak J, Richardson J, Medesan C, Antohe F, Radu C, Simionescu M, et al. Functional expression of the MHC class Irelated receptor, FcRn, in endothelial cells of mice. Int Immunol. 1998;10(9):1289-98.

40. Yip V, Palma E, Tesar DB, Mundo EE, Bumbaca D, Torres EK, et al. Quantitative cumulative biodistribution of antibodies in mice: effect of modulating binding affinity to the neonatal $\mathrm{Fc}$ receptor. mAbs. 2014;6(3):689-96.

41. Zhou J, Pop LM, Ghetie V. Hypercatabolism of IgG in mice with lupus-like syndrome. Lupus. 2005;14(6):458-66.

42. Liu X, Ye L, Christianson GJ, Yang JQ, Roopenian DC, Zhu X. NF-kappaB signaling regulates functional expression of the $\mathrm{MHC}$ class I-related neonatal $\mathrm{Fc}$ receptor for $\mathrm{IgG}$ via intronic binding sequences. J Immunol. 2007;179(5):2999-3011.

43. Christensen EI, Birn H, Storm T, Weyer K, Nielsen R. Endocytic receptors in the renal proximal tubule. Physiology (Bethesda). 2012;27(4):223-36.

44. Nagai J, Sato K, Yumoto R, Takano M. Megalin/cubilinmediated uptake of FITC-labeled IgG by OK kidney epithelial cells. Drug Metab Pharmacokinet. 2011;26(5):474-85.

45. Ogasawara S, Hosojima M, Kaseda R, Kabasawa H, YamamotoKabasawa $\mathrm{K}$, Kurosawa $\mathrm{H}$, et al. Significance of urinary fulllength and ectodomain forms of megalin in patients with type 2 diabetes. Diabetes Care. 2012;35(5):1112-8.

46. Tojo A, Onozato ML, Kurihara H, Sakai T, Goto A, Fujita T. Angiotensin II blockade restores albumin reabsorption in the proximal tubules of diabetic rats. Hypertens Res Off J Jpn Soc Hypertens. 2003;26(5):413-9.

47. Toblli JE, Cao G, Giani JF, Angerosa M, Dominici FP, GonzalezCadavid NF. Antifibrotic effects of pioglitazone at low doses on the diabetic rat kidney are associated with the improvement of markers of cell turnover, tubular and endothelial integrity, and angiogenesis. Kidney Blood Press Res. 2011;34(1):20-33.
48. Nielsen R, Mollet G, Esquivel EL, Weyer K, Nielsen PK, Antignac C, et al. Increased lysosomal proteolysis counteracts protein accumulation in the proximal tubule during focal segmental glomerulosclerosis. Kidney Int. 2013;84(5):902-10.

49. Richter WF, Bhansali SG, Morris ME. Mechanistic determinants of biotherapeutics absorption following SC administration. AAPS J. 2012;14(3):559-70.

50. Macdougall IC, Jones JM, Robinson MI, Miles JB, Coles GA, Williams JD. Subcutaneous erythropoietin therapy: comparison of three different sites of injection. Contrib Nephrol. 1991;88:152-6. discussion 7-8.

51. Olsson-Gisleskog P, Jacqmin P, Perez-Ruixo JJ. Population pharmacokinetics meta-analysis of recombinant human erythropoietin in healthy subjects. Clin Pharmacokinet. 2007;46(2):159-73.

52. Silva M, Poo J, Wagner F, Jackson M, Cutler D, Grace M, et al. A randomised trial to compare the pharmacokinetic, pharmacodynamic, and antiviral effects of peginterferon alfa- $2 b$ and peginterferon alfa-2a in patients with chronic hepatitis C (COMPARE). J Hepatol. 2006;45(2):204-13.

53. Summers LK, Samra JS, Humphreys SM, Morris RJ, Frayn KN. Subcutaneous abdominal adipose tissue blood flow: variation within and between subjects and relationship to obesity. Clin Sci (Lond). 1996;91(6):679-83.

54. Jonk AM, Houben AJ, de Jongh RT, Serne EH, Schaper NC, Stehouwer CD. Microvascular dysfunction in obesity: a potential mechanism in the pathogenesis of obesity-associated insulin resistance and hypertension. Physiology (Bethesda). 2007;22:252-60.

55. Villela NR, Kramer-Aguiar LG, Bottino DA, Wiernsperger N, Bouskela E. Metabolic disturbances linked to obesity: the role of impaired tissue perfusion. Arq Bras Endocrinol Metabol. 2009;53(2):238-45.

56. Frisbee JC. Hypertension-independent microvascular rarefaction in the obese Zucker rat model of the metabolic syndrome. Microcirculation. 2005;12(5):383-92. 